\title{
PREVALÊNCIA DA INTOXICAÇÃO EXÓGENA EM ADOLESCENTES E ADULTOS: UM ESTUDO EPIDEMIOLÓGICO NO ESTADO DO ESPÍRITO SANTO NO PERÍODO DE 2014 A 2020
}

\author{
PREVALENCE OF EXOGENOUS INTOXICATION IN ADOLESCENTS AND \\ ADULTS: AN EPIDEMIOLOGICAL STUDY IN THE STATE OF ESPÍRITO \\ SANTO FROM 2014 TO 2020
} \author{
Barros $^{2}$, Cosme Andrade de Almeida ${ }^{3}$. \\ ${ }^{1}$ Universidade Vila Velha, Vila Velha, ES, Brasil. \\ 2Universidad de Aquino Bolívia, Santa Cruz de la Sierra, Bolivia. \\ ${ }^{3}$ Universidade do Estado da Bahia, Teixeira de Freitas, BA, Brasil. \\ *laralonguiuvv@gmail.com
}

Lara Vargas Longui ${ }^{1 *}$, Bárbara Ferraz Barbosa ${ }^{2}$, Magna Cristina Rocha

\section{RESUMO}

A intoxicação exógena é representada por um conjunto de alterações clínicas decorrentes do envenenamento provocado pela exposição à substancias químicas em altas doses. Mediante o estudo objetivou-se verificar a prevalência da intoxicação exógena em adolescentes e adultos no estado do Espírito Santo, analisando os fatores de risco associados à macrorregião de saúde Metropolitana. Foi realizado um estudo epidemiológico, transversal, descritivo com base na coleta de dados secundários, por meio do Sistema de Agravos de Notificação disponibilizados no banco de dados DATASUS - TABNET sobre a prevalência da intoxicação exógena no estado do Espirito Santo. Os dados coletados do estado do Espirito Santo foram filtrados para a macrorregião de saúde Metropolitana, onde foi possível observar os municípios de maior notificação, faixa etária (15 a 59 anos), agente tóxico e a circunstância de uso no período de 2014 a 2020. Foram registrados 21.681 casos de intoxicação exógena em adolescentes e adultos no estado do Espírito Santo, notificados no período de 2014 a 2020. Por meio da coleta de dados referente à macrorregião de saúde Metropolitana, observa-se um valor total de 12.480 casos notificados, com maior incidência nas cidades de Vitória com 4.649 casos, Serra com 2236 casos e de Vila Velha com 1486 casos. Realizou-se um levantamento dos agentes tóxicos, onde o grupo de medicamentos ocupa a posição de maior risco com 6569 notificações, seguido por drogas de abuso com 1386 casos. A faixa etária mais acometida foi composta pelos adultos, representando $80,6 \%$ do total. $\mathrm{Na}$ parcela populacional dos adolescentes $(19,3 \%)$ há um predomínio aproximado de cinco vezes mais intoxicações por medicamento em relação a drogas de abuso, sendo este um grupo com valor percentual aproximado ao de alimentos e bebidas nessa faixa etária. Em relação ao sexo, a prevalência da intoxicação em mulheres é cerca de quatro vezes maior do que em homens, tendo como principal circunstancia a tentativa de suicídio. Constatou-se que as intoxicações exógenas da macrorregião Metropolitana de saúde, quando comparadas a todo o estado do Espírito Santo, possuem valores significativos, acometendo, predominantemente, mulheres por meio da ingestão descontrolada de fármacos, tendo uso principal a tentativa de suicídio, mostrando a 
necessidade de campanhas relacionadas ao cuidado com a automedicação e abuso medicamentoso.

Palavras-chave: Abuso de substâncias. Dependência química. Drogadição. Drogas de abuso. Intoxicação por medicamentos. 